Kruijsen-Terpstra, A.J.A., Verschuren, O., Ketelaar, M., Riedijk, L., Gorter, J.W., Jongmans, M.Jר Boeije, H. Parents' experiences and needs regarding physical and occupational therapy for their young children with cerebral palsy. Research in Developmental Disabilities: 2016, 53-54(6-7 7), 314-322 nivel

\begin{tabular}{|l|l|}
$\begin{array}{l}\text { Postprint } \\
\text { Version }\end{array}$ & 1.0 \\
\hline Journal website & http://www.sciencedirect.com/science/article/pii/S0891422216300336 \\
\hline Pubmed link & $\underline{\text { http://www.ncbi.nlm.nih.gov/pubmed/26970858 }}$ \\
\hline DOI & $10.1016 /$ j.ridd.2016.02.012
\end{tabular}

This is a NIVEL certified Post Print, more info at http://www.nivel.eu

\title{
Parents' experiences and needs regarding physical and occupational therapy for their young children with cerebral palsy
}

\author{
ANNE J.A. KRUIJSEN-TERPSTRA ${ }^{\text {A, B, }}$, OLAF VerSChUREN ${ }^{\text {A, B, 1, }}$, MARJOLIJN KETELAAR R, B, \\ LARISA RIEDIJK ${ }^{\mathrm{C}}$, JAN WILLEM GORTER ${ }^{\mathrm{B}, \mathrm{D}, 2,}$, MARIAN J. JONGMANS ${ }^{\mathrm{B}, \mathrm{E}, \mathrm{F}, 3,}$, HENNIE BOEIJE ${ }^{\mathrm{G},}$ \\ 4 ,
}

\section{HIGHLIGHTS}

- Experiences and needs of parents regarding therapy of their young child with $\mathrm{CP}$ were investigated.

- Main themes were: information, communication, partnership and the process of parent empowerment.

- Experiences and needs differed between parents and changed over time.

\author{
Abstract \\ Objective \\ To explore the experiences and needs of parents of young children (aged 2-4 \\ years) with cerebral palsy $(\mathrm{CP})$ regarding their child's physical and occupational \\ therapy process in a rehabilitation setting. \\ Methods
}

A qualitative design was used involving semi-structured interviews with 21 parents of young children with CP. Interviews were conducted until informational redundancy was achieved.

Results

Three major themes were identified: Information, communication and partnership. A fourth, overarching theme emerged: The process of parent empowerment. Experiences and needs differed between parents and changed over time.

Conclusion

This study suggests that various themes play a key role in the experiences and needs of parents of young children with CP. The identified themes provide important insights into how and why service providers might change their approach.

Practice implications

Becoming empowered is a dynamic process for parents, in which both parents and service providers play a role. Service providers should continually adapt 
Kruijsen-Terpstra, A.J.A., Verschuren, O., Ketelaar, M., Riedijk, L., Gorter, J.W., Jongmans, M.Jר Boeije, H. Parents' experiences and needs regarding physical and occupational therapy for their young children with cerebral palsy. Research in Developmental Disabilities: 2016, 53_54(6-7 7), 314-322

their role to parents' needs of information, communication and partnership, and they should support and facilitate parents in becoming empowered. For that, service providers should be educated on the process of parent empowerment, on ways to facilitate this process and on the importance of involving and interacting with parents.

This allows families of young children with $\mathrm{CP}$ to be provided with services that best suit their needs.

\section{INTRODUCTION}

The most common physical disability affecting children is cerebral palsy $(\mathrm{CP})$, with a prevalence of 2 to 2.5 per 1000 live births (Dolk et al., 2006, Hutton and Pharoah, 2006 and Oskoui et al., 2013). CP is the general term for a number of neurological conditions that affect movement and co-ordination. Children with $\mathrm{CP}$ often receive physical and occupational therapy to optimize their development. A key concept in the treatment of children with CP is Family-Centered Care (King \& Chiarello, 2014). Family-Centered Care comprises listening to families and being responsive to their priorities and needs, and developing an equal partnership between service providers and parents, in order to promote the families' engagement (King \& Chiarello, 2014). Parental engagement in children's therapy is essential, since it has been suggested that parents' early beliefs regarding their child's therapy might have consequences for treatment participation, and potentially also for treatment outcomes (Nock, Ferriter, \& Holmberg, 2007). Furthermore, Family-Centered Care is also believed to facilitate the process of empowerment (King \& Chiarello, 2014), referring to the process of families gaining control over their lives (Singh et al., 1995). Parents of young children with CP not only have to adapt to raising a child, but are also engaged in a process of adapting to having a child with a disability (Piggot et al., 2002 and Rentinck et al., 2007). This adaptation process might involve parents of younger children having different experiences and needs than parents of older children, so in examining the experiences and needs of parents, it is important to distinguish between parents of younger children and those of older children. Based on a recent literature review on parents' experiences with physical and occupational therapy for their young child with CP (Kruijsen-Terpstra et al., 2013), a framework was constructed to describe the experiences of parents of young children with CP regarding the interventions their child receives (Kruijsen-Terpstra et al., 2013). However, only three of the thirteen studies included in the review explicitly focused on parents of young children (Hinojosa, 1990, Hinojosa and Anderson, 1991 and Øien et al., 2010). Most studies failed to describe in detail the roles of parents in the children's interventions. The extent of parental involvement may have influenced parents' experiences. In addition, since the experiences and needs of parents of young children might be affected by the parents' process of adapting to having a child with a disability, there is a need for more studies explicitly focusing on the experiences of parents with young children with CP (Kruijsen-Terpstra et al., 2013).

Greater understanding of the perspectives of parents of young children might facilitate therapists in providing services that suit the family's needs, maximizing opportunities for parental engagement in their child's therapy and, ultimately, 
Kruijsen-Terpstra, A.J.A., Verschuren, O., Ketelaar, M., Riedijk, L., Gorter, J.W., Jongmans, M.Jר Boeije, H. Parents' experiences and needs regarding physical and occupational therapy for their young children with cerebral palsy. Research in Developmental Disabilities: 2016, 53-54(6-7 7), 314-322

optimizing the health outcomes of the child with $\mathrm{CP}$ and the family. The objective of the present qualitative study was to explore the experiences and needs of parents of young children (aged 2-4 years) with CP regarding their child's physical and occupational therapy process in a rehabilitation setting.

\section{METHODS}

\subsection{Design and study sample}

The experiences of parents of young children (aged 2-4 years) with CP were explored using qualitative semi-structured interviews. This study was done in the context of a larger study (LEARN 2 MOVE 2-3 Study) in which parents and their children participated. The LEARN 2 MOVE 2-3 Study evaluated the efficacy and working mechanisms of two intervention approaches, compared to regular care (Ketelaar et al., 2010). During the LEARN 2 MOVE 2-3 Study all children received physical and/or occupational therapy in a rehabilitation setting in the Netherlands. Additionally, the context of the LEARN 2 MOVE 2-3 Study allowed us to examine parental involvement in the intervention procedures in the three intervention groups (child-focused, context-focused and regular care). Parents often reported that they did not notice any differences in the content or process of their child's therapy before or during the LEARN 2 MOVE 2-3 Study. Therefore, parents' experiences and needs regarding their child's therapy are reported for the whole group of interviewed parents.

Once a child had completed the LEARN 2 MOVE 2-3 intervention, his or her parents were recruited to participate in this qualitative study. A purposive sampling approach was used to ensure that parents of all three intervention groups were included. Recruitment of parents continued until the interviewers indicated that informational redundancy had been achieved. In total, 23 of the 68 families were invited to take part in this qualitative study. Two of the 23 invited families did not want to participate in the interviews due to lack of time. In two of the 21 interviewed families, both parents were present during the interview; in all other cases, only the mother was interviewed. All parents signed informed consent. The Medical Ethics Committee of the University Medical Centre Utrecht, The Netherlands, approved this qualitative study.

\subsection{Interviews}

The interviews were conducted at the families' homes by one of three trained interviewers. The interviewers were guided by a topic list (see Table 1). In order to create an open atmosphere, the interview started with an open-ended question about the parents' considerations that had played a role in their decision to participate in the LEARN 2 MOVE 2-3 study (Britten, 1995 and Dicicco-Bloom and Crabtree, 2006). This was followed by more in-depth open-ended questions. Rephrasing and probing were used to obtain a better understanding. Each interview was recorded and the interviewer took notes. After every third interview, the interviewers and the researcher discussed whether any new topics had emerged. Each interview lasted for $45-90 \mathrm{~min}$. 
Kruijsen-Terpstra, A.J.A., Verschuren, O., Ketelaar, M., Riedijk, L., Gorter, J.W., Jongmans, M.Jר Boeije, H. Parents' experiences and needs regarding physical and occupational therapy for their young children with cerebral palsy. Research in Developmental Disabilities: 2016, 53-54(6-7 7), 314-322

\section{[TABLE 1. ]}

\subsection{Data management and analysis}

The interviews were recorded and transcribed verbatim with accompanying field notes, and entered into NVIVO 10. Data were analyzed by a thematic analysis approach (Braun \& Clarke, 2006). Three phases of coding - open, axial, and selective - were used in the analysis to identify relevant excerpts from the interviews and then cluster the data into themes relevant to the research (Boeije, 2010). During the open coding phase all text was read and then the categories and themes that emerged from the data were labeled. Next, the relationships between the categories or themes were identified during the axial coding phase. During the selective coding phase the core themes were identified.

The transcribed interviews were read independently by two researchers (AK and LR) to identify emerging themes. The first transcribed interview was also read and discussed by a third researcher (HB). Subsequently, the two researchers (AK and LR) analyzed and discussed the other interviews and identified main themes by grouping together related subthemes. After the twelfth interview, no new themes or subthemes were found in the analysis, so informational redundancy had been achieved. The other nine interviews were analyzed to verify and strengthen the themes.

\section{RESULTS}

In parents' experiences with their child's therapy, three major themes were identified: Information, communication and partnership. Within these major themes, several subthemes were identified (see Table 2). Furthermore, a fourth, overarching theme emerged: The parental empowerment process. This theme refers to the process of empowerment that parents of young children with $\mathrm{CP}$ experience, and its interplay with their needs for information, communication and partnership.

\section{[TABLE 2.]}

\subsection{Information}

Parents often expressed a need for information, in particular information on CP in general, information regarding their child's therapy and information about what to expect for their child's future. Parents reported that their informational needs were not always met.

Over time, most parents became more familiar with the rehabilitation setting and their child's condition. When parents felt they were becoming more empowered, this was reflected in changes in their informational needs and priorities.

The first time I was asked that question [defining the child's therapeutic needs], I thought 'What?'. What should I ask for? How can my child become healthy? So my response was, like, 'What?' So the first few times I asked nothing. But then you get to talk to parents who have been faced with this for some time, and you get some information: 'Oh, yes, that's something you can ask. Right, about toilet training, that's a good question.' So you start to think differently about the way they think.

\subsubsection{Information on $\mathrm{CP}$ in general}


Kruijsen-Terpstra, A.J.A., Verschuren, O., Ketelaar, M., Riedijk, L., Gorter, J.W., Jongmans, M.Jר Boeije, H. Parents' experiences and needs regarding physical and occupational therapy for their young children with cerebral palsy. Research in Developmental Disabilities: 2016, 53-54(6-7 7), 314-322

Many parents reported having had an urgent desire for general information on $\mathrm{CP}$ when their child just started therapy at the rehabilitation center. Parents mentioned that it was difficult for them to ask for specific information at a time when they were still quite unfamiliar with their child's diagnosis and the rehabilitation setting. Parents reported that they appreciated it when therapists took the initiative in providing this general information.

Yeah, that [i.e. information on the way children with CP can function in society] is what I really missed! You enter a world that you know nothing whatsoever about. You leave the hospital with the child and they tell you 'Well, keep track of its development'. And that's about it.

\subsubsection{Therapy}

A substantial proportion of the parents reported that they were not aware of what was actually happening during their child's therapy. Some of these parents did not feel they needed more information about the content of their child's therapy, whereas others expressed a desire for more information. Parents often wanted more information to enable them to practice with their child at home. It was especially parents who thought of themselves as lay people and did not feel to be an expert yet who wanted to benefit from the therapists' expertise and get information from them, for example in choosing the best intervention for their child.

If you have to decide for yourself then I wouldn't really know how to do that. What goals you can set, or will she actually be able to do this in three months' time? So I'd think, 'We'll have to wait and see, you know?' And then the others [i.e. therapists] would be fully convinced: 'Yes I think so.' But they know much more about it than we, of course, so I'd always appreciate it when they did that.

\subsubsection{Information on prospects}

Most parents expressed the desire for their child to be able to live independently in the future. These parents often reported a need for information on what would be realistic to expect for their child's future. Parents often experienced disappointments about their child's progress. Some parents reported that they tried to protect themselves, and no longer dared to have expectations about their child's development.

Yeah, we're always very neutral about it, so that it's all good. So it's not that you expect something and then you're disappointed.

\subsection{Communication}

Communication was a major theme in the experiences of parents regarding their child's therapy. The communication between parents and therapists mainly focused on reporting what the child's day at the center had been like, often in the form of a written diary. The written diary did not meet all of the parents' needs for communication. Some parents preferred to have face-to-face contact, or to call or email the therapist. Parents' preferences for the mode of communication were related to several contextual factors. For example, some parents said they highly appreciated the written diary method, since it best fitted their busy lives, while other parents who had to cope with health issues of their child expressed the need for more extensive communication. In addition to the daily communication, parents had occasional meetings with the therapists at the center. 
Kruijsen-Terpstra, A.J.A., Verschuren, O., Ketelaar, M., Riedijk, L., Gorter, J.W., Jongmans, M.Jר Boeije, H. Parents' experiences and needs regarding physical and occupational therapy for their young children with cerebral palsy. Research in Developmental Disabilities: 2016, 53-54(6-7 7), 314-322

\subsubsection{Attentiveness in communication}

In general, parents valued it when therapists showed a personal interest in them. That they [the therapists] regard you as parents, that they listen to you and that they act upon what you say. So that you can see you're being listened to. That's just about the most important thing.

Parents expressed three types of needs regarding interest on the part of the therapist. First, parents stated that they wanted to be listened to by therapists and not merely receive information from them. Parents often preferred a two-way communication, and wanted to have the ability to bring up subjects themselves and to ask questions. Second, some parents explicitly expressed the need for more personal attention from and personal contact with the therapists. These parents indicated that it was important for them that the therapist listened carefully to them as a parent and valued their opinions. For example, a mother said that it was important that the therapists paid attention to her knowledge, since she was the one that who saw her child every day and hence was the best judge of how things were going. Third, some parents expressed the desire for personal encouragement by the therapists.

That's indeed what I miss sometimes. Just a little personal chat. Or sometimes you need some encouragement from the physical therapist, like 'You know, you could also do it like this,' and I'm not getting that now.

\subsubsection{Honesty in communication}

Parents expressed the need for openness in communication. Honesty and transparency in communication were highly valued even when difficult decisions had to be taken or when therapists had bad news.

They're usually very honest about it and tell you exactly how it is, and don't beat about the bush. I appreciate that.

Some parents had experienced that therapists did not tell them everything. Lack of openness in communication hampered the development of an equal partnership between parents and therapists, so most parents rather preferred the therapists to share things with them in an open atmosphere.

I think honesty is very important. We've had situations where things simply were not told us. I prefer to have everything told to me, even if things are not well, so we can work on them together.

\subsection{Partnership between parents and therapists}

Parents and therapists often built up a partnership concerning the child's interventions. This was especially evident when it came to making decisions. The growth of this partnership depended on both parents and therapists. The roles of parents and therapists and the extent to which parents wanted to be involved influenced the development of the partnership.

\subsubsection{Roles in partnership}

The different roles of parents were particularly apparent in goal setting. Three types of roles in goal setting could be distinguished; therapists taking the lead (i.e., goals were based exclusively on therapists' opinion), partnerships involving dialogue between parents and therapists, or, in exceptional cases, parents taking the lead (i.e., goals were based exclusively on the parents' opinion). 
Kruijsen-Terpstra, A.J.A., Verschuren, O., Ketelaar, M., Riedijk, L., Gorter, J.W., Jongmans, M.Jר Boeije, H. Parents' experiences and needs regarding physical and occupational therapy for their young children with cerebral palsy. Research in Developmental Disabilities: 2016, 53_54(6-7 7), 314-322

Goals were often exclusively set by therapists when parents reported that they regarded themselves as a lay people, and said that they had no idea what would be a suitable goal for their child. These parents indicated that they preferred the therapists to be in charge of setting therapy goals for their child, because they expected and trusted therapists to know what would be best for their child. Some of the parents preferred the therapist taking the lead in goal setting because they wished to be "only a parent" to their child. Some of the parents were involved in the goal setting process to some extent. These parents often appreciated that the goals reflected both what they perceived as important and what the therapists thought would be important to work on. Some of the parents appreciated it when therapists would guide them through the process of goal setting, for example by means of a questionnaire. You know what you consider to be important, but there are also other things that may be very practical, and that you might not think of yourself. So I really appreciated that, first using the questionnaire to check what he can and can't do yet, and then setting the goals.

A few parents felt they became more capable in goal setting over time, since they were then better informed regarding the child's condition and what to expect.

\subsubsection{Involvement of parents in their child's therapy}

There was much diversity in parents' experiences and needs regarding their involvement in their child's therapy. The extent to which parents were involved varied from only reading the child's diary to active participation in goal setting and practicing at home. Parental needs for involvement were related to their role. Roughly, three types of parents could be distinguished; (1) parents who thought of themselves as lay persons, (2) parents who perceived themselves to be experts on their own child, and (3) parents who were somewhere in between. The parents perceiving themselves as lay persons often did not feel called upon to be involved. These parents thought the therapists were "the experts" and often preferred to leave things up to them.

I don't feel I have to do something, let's put it like that ... No, not at all. ... I leave it all to the experts. No, I absolutely don't want to interfere in that, no.

On the other hand, there were parents who perceived themselves as the experts, who wanted to be highly involved in their child's interventions and desired to be on top of everything and to be in control. However, some of these parents indicated that the therapists sometimes made them feel that it was not a good idea for them as parents to be actively involved in their child's therapy. Some of the parents reported that they would have appreciated it if the therapist had involved them more in their child's therapy. In addition, there were parents who thought of themselves as somewhere in between lay persons and experts, but said they would have liked to have been more fully involved, for instance as regards practicing at home, but they now often did not feel capable of doing so.

\subsection{Process of parent empowerment}

The needs in the therapy process not only differed between parents, but a parent's needs were also found to change over time. Many of the interviewed parents reported that they had perceived themselves as lay people at the time when their child started therapy at the rehabilitation center. Overtime most parents felt more competent, i.e., more empowered. The course of the process of parent empowerment was found to be 
Kruijsen-Terpstra, A.J.A., Verschuren, O., Ketelaar, M., Riedijk, L., Gorter, J.W., Jongmans, M.Jר Boeije, H. Parents' experiences and needs regarding physical and occupational therapy for their young children with cerebral palsy. Research in Developmental Disabilities: 2016, 53-54(6-7 7), 314-322

different for each parent. This was mainly due to contextual factors. Often, multiple factors were involved simultaneously, so the influence of factors was not always straightforward as regards facilitating or inhibiting the parent empowerment process. Furthermore, the contextual factors were often found to be unique to a family.

\section{DISCUSSION AND CONCLUSION}

\subsection{Discussion}

A great deal of variation was found in the experiences and needs of parents of young children with CP regarding their child's physical and occupational therapy. This could partly be explained by the stage of the process of empowerment that parents were in; for example parents who thought of themselves as lay people had different needs in information than person who felt to be in control. The course of this process of parent empowerment seemed to be related to the family's context, making this a dynamic and unique process for each family.

The importance of information, communication and partnership in pediatric care is widely acknowledged in the literature on Family-Centered Care (Arango, 2011 and King and Chiarello, 2014; Kuo et al., 2012). Achieving Family-Centered Care is often found to be a challenge in practice (Darrah, Wiart, Magill-Evans, Ray, \& Andersen, 2012Kuo et al., 2012 and MacKean et al., 2005).

\subsubsection{Partnership and empowerment}

An essential part of Family-Centered Care is true collaboration between parents and service providers. However, many parents in our study reported that they had perceived themselves as lay persons in the early stages of their child's rehabilitation, resulting in inequality between parents and therapists. Although many patients generally perceive the professionals to be the experts (Joseph-Williams, Elwyn, \& Edwards, 2014), this might be more explicit in parents of young children with CP. Over time, as parents become more knowledgeable about their child's condition, their roles and needs should evolve (Feldman, Ploof, \& Cohen, 1999). As parents become more knowledgeable and feel more capable, the service providers' role should ideally evolve over time from directing to teaching, collaborating and finally supporting (Feldman et al., 1999).

\subsubsection{Information and empowerment}

Furthermore, attention needs to be given to the parents' need for information, which was expressed by the parents in our study and is also confirmed by the literature (Alsem et al., 2014 and Siebes et al., 2012; Van der Pal et al., 2014). Providing families with general information is often a challenge for service providers and needs to be further improved to facilitate the parent empowerment process (Jeglinsky, Autti-Ramo, \& Brogren Carlberg, 2012). Parents of young children with CP can benefit from patient information materials on their child's diagnosis and prospects, on Family-Centered Care and on how they themselves can contribute in their own way to their child's treatment. In addition, contact with fellow parents, for instance at parent meetings, may also provide support (Shilling et al., 2013). The access to these kinds of information enables parents to gain control and will thereby enhance their empowerment process (Singh et al., 1995). 
Kruijsen-Terpstra, A.J.A., Verschuren, O., Ketelaar, M., Riedijk, L., Gorter, J.W., Jongmans, M.Jר Boeije, H. Parents' experiences and needs regarding physical and occupational therapy for their young children with cerebral palsy. Research in Developmental Disabilities: 2016, 53-54(6-7 7), 314-322

\subsubsection{Communication and empowerment}

In the Netherlands, physical and occupational therapy for young children with $\mathrm{CP}$ is typically provided in rehabilitation centers, often without the parents being present during therapy. Communication between parents and therapists usually takes place in form of a written diary. Although some of the parents appreciated this written diary method, it did not fulfill the needs for communication of all parents. The unfulfilled needs that parents expressed on communication relate to parents wanting to be heard by therapists. It was appreciated when therapists tried to interact with the parents. In the Dutch therapy setting parents often have only once in a while real face-to-face contact with the therapist. The absence of parents during their child's therapy makes it more difficult for therapists to fine-tune the treatment to the parent's needs, to support parents in their empowerment process and shifting roles and to establish true partnership. Constant fine-tuning over time between the roles of therapists and parents and parents involvement in their child's therapy is essential, since the parents' progress in the empowerment process and the influences of contextual factors were found to change over time. To be able to meet parents' communicational needs and preferences, therapists should interact with parents.

\subsubsection{Service providers}

Although service providers should be aware of contextual factors reported by children and their parents, awareness alone might not be enough. Moreover, the parent empowerment process is not only a matter for the parents themselves, as service providers are supposed to support the child with the disability, but also support and coach the child's family. In order to facilitate parent empowerment, service providers should provide an environment based on support, mutual trust and shared decision making (Panicker, 2013). Therefore, providing children with chronic conditions with optimal interventions requires educating service providers on the process of parent empowerment, on ways to facilitate this process and on the importance of involving parents and interacting with them (Gorter, Visser-Meily, \& Ketelaar, 2010). As a consequence, service providers should also be trained to adapt their role more closely to the individual families.

\subsubsection{Limitations}

Our findings must be interpreted in the light of certain limitations of the study. Since the cultural context and organizational structure of rehabilitation for young children with CP varies among countries, the experiences of the families who participated in this study may differ from those of families living in other countries. Moreover, the children who participated in this study were classified at GMFCS levels I-IV. Since the parents' process of adapting to their child's diagnosis is affected by the severity of the motor disability (Schuengel et al., 2009), it is important to consider that some of the themes and topics described in this study might not reflect the experiences of families with children with severe disabilities. In interpreting the results, it should be considered that our children received physical and occupational therapy within the context of the LEARN 2 MOVE 2-3 study, which may have caused possible bias in the selection of parents. 
Kruijsen-Terpstra, A.J.A., Verschuren, O., Ketelaar, M., Riedijk, L., Gorter, J.W., Jongmans, M.Jר Boeije, H. Parents' experiences and needs regarding physical and occupational therapy for their young children with cerebral palsy. Research in Developmental Disabilities: 2016, 53_54(6-7 7), 314-322

\subsection{Practice implications}

There is no such thing as one approach or trajectory that can be applied to all families of young children with CP in order to meet parents' needs. Needs differ between parents and change over time. Especially empowerment is found to be a dynamic process in which both parents and service providers play a role. Consequently, service providers should continually interact with parents and finetune their roles in order to know parents' needs and at where parents are in their empowerment process (Feldman et al., 1999). Furthermore, service providers should adapt their role in the partnership with the parents to the parent's needs and to the empowerment process that parents are in, and should support and facilitate parents in becoming empowered. Service providers should be educated on the process of parent empowerment, on ways to facilitate this process and on the importance of involving and interacting with parents. This will allow families of young children with CP to be provided with services that best suit their needs.

\subsection{Conclusion}

Information, communication and partnership, and the process of parent empowerment are important themes in parents' experiences and needs regarding their young child's therapy. Experiences and needs varied between parents and individual parents' experiences and needs changed over time. To be able to provide young children with $\mathrm{CP}$ with the best care, and to support their parents, service providers should be educated on the process of parent empowerment, on ways to facilitate this process, and on the importance of involving parents and interacting with them.

\section{Declaration of conflicting interest}

The authors declare that they have no competing interests with respect to the research, authorship, and/or publication of this article.

\section{Acknowledgements}

The authors are grateful to all parents who took part in this qualitative study, for their willingness to share their experiences. We also sincerely thank all of the children and their parents, and the participating rehabilitation centers, for their willingness to participate in the LEARN 2 MOVE 2-3 study. Furthermore we would like to thank the interviewers, Astrid Onderwater, Sjoukje Schuttel and Mirte Wel, for conducting the interviews, Eric Huyzer, parent of a child with CP, and Johannes Verheijden, policy advisor of BOSK, for sharing their knowledge and thoughts with us. We are grateful to Professor E. Lindeman ${ }^{\dagger}$ for her contribution to the research program. The following members of the LEARN 2 MOVE 2-3 Study Group contributed to this study: M. Verhoef (De Hoogstraat Rehabilitation, Utrecht), A.F. Titulaer (Rijndam Rehabilitation Institute, Rotterdam), M. Meinsma-van der Tuin (Rehabilitation Center 'Revalidatie Friesland', Beetsterzwaag), Y.M. van de Laar-Bakker (Vogellanden, Center for Rehabilitation, Zwolle), J.C. van Munster (Sint Maartenskliniek, Department of Paediatric Rehabilitation, Nijmegen), M.J.P.M. Geerts (Rehabilitation Centre Leijpark, Libra Rehabilitation Medicine \& Audiology, Tilburg), J.M. Voorman (Merem Rehabilitation Center De Trappenberg, Huizen), L. van Vulpen (Amsterdam Rehabilitation Research Center| Reade, Amsterdam), C.A. Luijten-Ansems (Revant Rehabilitation Centre Breda, Breda), H. Gorter (Roessingh Rehabilitation Centre, Enschede), Y.J.M. Janssen-Potten (Adelante Centre of expertise in Rehabilitation and Audiology, Hoensbroek), H.A.J.M. van den Heuvel 
Kruijsen-Terpstra, A.J.A., Verschuren, O., Ketelaar, M., Riedijk, L., Gorter, J.W., Jongmans, M.J匇 Boeije, H. Parents' experiences and needs regarding physical and occupational therapy for their young children with cerebral palsy. Research in Developmental Disabilities: 2016, 53_54(6-7 7), 314-322

(Child Expertise Centre, Tolbrug Specialistic Rehabilitation's-Hertogenbosch), and F.D. van der Hoek (Center for Rehabilitation, University Medical Center Groningen, University of Groningen, Groningen).

This study is part of the Dutch national LEARN 2 MOVE research program and is supported financially by ZonMw (grant number 89000002), Johanna Kinderfonds, Stichting Rotterdams Kinderrevalidatie Fonds Adriaanstichting, Revalidatiefonds, Phelps Stichting, Revalidatie Nederland, and the Nederlandse Vereniging van Revalidatieartsen.

\section{REFERENCES}

M.W. Alsem, R.C. Siebes, J.W. Gorter, M.J. Jongmans, B.G. Nijhuis, M. Ketelaar Assessment of family needs in children with physical disabilities: Development of a family needs inventory Child: Care, Health and Development, 40 (2014), pp. 498-506

P. Arango Family-centered care Academic Pediatrics, 11 (2011), pp. 97-99

$\mathrm{H}$. Boeije Analysis in qualitative research SAGE, London (2010)

V. Braun, V. Clarke Using thematic analysis in psychology Qualitative Research in Psychology, 3 (2006), pp. 77-101

N. Britten Qualitative interviews in medical research BMJ (Clinical Research Ed.), 311 (1995), pp. 251-253

J. Darrah, L. Wiart, J. Magill-Evans, L. Ray, J. Andersen Are family-centred principles, functional goal setting and transition planning evident in therapy services for children with cerebral palsy? Child: Care, Health and Development, 38 (2012), pp. 41-47

B. Dicicco-Bloom, B.F. Crabtree The qualitative research interview Medical Education, 40 (2006), pp. 314-321

H. Dolk, J. Parkes, N. Hill Trends in the prevalence of cerebral palsy in Northern Ireland, 1981-1997 Developmental Medicine and Child Neurology, 48 (2006), pp. 406-412

H.M. Feldman, D. Ploof, W.I. Cohen Physician-family partnerships: The adaptive practice model Journal of Developmental and Behavioral Pediatrics: JDBP, 20 (1999), pp. 111-116 J.W. Gorter, A. Visser-Meily, M. Ketelaar The relevance of family-centred medicine and the implications for doctor education Medical Education, 44 (2010), pp. 332-334

J. Hinojosa How mothers of preschool children with cerebral palsy perceive occupational and physical therapists and their influence on family life Occupational Therapy Journal of Research, 10 (1990), pp. 144-160

J. Hinojosa, J. Anderson Mothers' perceptions of home treatment programs for their preschool children with cerebral palsy The American Journal of Occupational Therapy, 45 (1991), pp. 273-279 Official Publication of the American Occupational Therapy Association J.L. Hutton, P.O. Pharoah Life expectancy in severe cerebral palsy Archives of Disease in Childhood, 91 (2006), pp. 254-258

Jeglinsky, I. Autti-Ramo, E. Brogren Carlberg Two sides of the mirror: Parents' and service providers' view on the family-centredness of care for children with cerebral palsy Child: Care, Health and Development, 38 (2012), pp. 79-86

N. Joseph-Williams, G. Elwyn, A. Edwards Knowledge is not power for patients: A systematic review and thematic synthesis of patient-reported barriers and facilitators to shared decision making Patient Education and Counseling, 94 (2014), pp. 291-309 M. Ketelaar, A.J. Kruijsen, O. Verschuren, M.J. Jongmans, J.W. Gorter, J. Verheijden, et al. LEARN 2 MOVE 2-3: A randomized controlled trial on the efficacy of child-focused intervention and context-focused intervention in preschool children with cerebral palsy BMC Pediatrics, 10 (2010), p. 80

G. King, L. Chiarello Family-centered care for children with cerebral palsy: Conceptual and practical considerations to advance care and practice Journal of Child Neurology, 29 (2014), pp. 1046-1054

A.J. Kruijsen-Terpstra, M. Ketelaar, H. Boeije, M.J. Jongmans, J.W. Gorter, J. Verheijden, et al. Parents' experiences with physical and occupational therapy for their young child with cerebral palsy: A mixed studies review Child: Care, Health and Development, 40 (2013), pp. $787-796$ 
Kruijsen-Terpstra, A.J.A., Verschuren, O., Ketelaar, M., Riedijk, L., Gorter, J.W., Jongmans, M.Jר Boeije, H. Parents' experiences and needs regarding physical and occupational therapy for their young children with cerebral palsy. Research in Developmental Disabilities: 2016, 53_54(6-7 7), 314-322

D.Z. Kuo, A.J. Houtrow, P. Arango, K.A. Kuuhlthau, J.M. Simmons, J.M. Neff Family-centred care: Current applications and future directions in pediatric health care Maternal and Child Health Journal, 16 (2012), pp. 297-305

G.L. MacKean, W.E. Thurston, C.M. Scott Bridging the divide between families and health professionals' perspectives on family-centred care Health Expectations, 8 (2005), pp. 74-85 An International Journal of Public Participation in Health Care and Health Policy M.K. Nock, C. Ferriter, E. Holmberg Parent beliefs about treatment credibility and effectiveness: Assessment and relation to subsequent treatment participation Journal of Child and Family Studies, 16 (2007), pp. 27-38

Øien, B. Fallang, S. Østensjø Goal-setting in paediatric rehabilitation: Perceptions of parents and professional Child: Care, Health and Development, 36 (2010), pp. 558-565 M. Oskoui, L. Joseph, L. Dagenais, M. Shevell Prevalence of cerebral palsy in Quebec: Alternative approaches Neuroepidemiology, 40 (2013), pp. 264-268

L. Panicker Nurses' perceptions of parent empowerment in chronic illness Contemporary Nurse, 45 (2) (2013), pp. 210-219

J. Piggot, J. Paterson, C. Hocking Participation in home therapy programs for children with cerebral palsy: A compelling challenge Qualitative Health Research, 12 (2002), pp. 11121129

I.C. Rentinck, M. Ketelaar, M.J. Jongmans, J.W. Gorter Parents of children with cerebral palsy: A review of factors related to the process of adaptation Child: Care, Health and Development, 33 (2007), pp. 161-169

C. Schuengel, I.C. Rentinck, J. Stolk, J.M. Voorman, G.M. Loots, M. Ketelaar, et al. Parents' reactions to the diagnosis of cerebral palsy: Associations between resolution, age and severity of disability Child: Care, Health and Development, 35 (2009), pp. 673-680

V. Shilling, C. Morris, J. Thompson-Coon, O. Ukoumunne, M. Rogers, S. Logan Peer support for parents of children with chronic disabling conditions: A systematic review of quantitative and qualitative studies Developmental Medicine and Child Neurology, 55 (2013), pp. 602-609

R.C. Siebes, M. Ketelaar, J.W. Gorter, M. Alsem, M.J. Jongmans Needs of families with children who have a physical disability: A literature review Critical Reviews in Physical and Rehabilitation Medicine, 24 (2012), pp. 85-108

N. Singh, W.J. Curtis, C.R. Ellis, M.W. Nicholson, T.M. Villani, H.A. Wechsler Psychometric analysis of the family empowerment scale Journal of Emotional and Behavioral Disorders, 3 (1995), pp. 85-91

S.M. Van der Pal, L.L. Alpay, G.J. Van Steenbrugge, S.B. Detmar An exploration of parents' experiences and empowerment in the care for preterm born children Journal of Child and Family Studies, 23 (2014), pp. 1081-1089 
Kruijsen-Terpstra, A.J.A., Verschuren, O., Ketelaar, M., Riedijk, L., Gorter, J.W., Jongmans, M.Jר Boeije, H. Parents' experiences and needs regarding physical and occupational therapy for their young children with cerebral palsy. Research in Developmental Disabilities: 2016, 53-54(6-7 7), 314-322

\section{TABLES}

Table 1

Main topics from the interview guide, with one example question for each topic.

\begin{tabular}{|c|c|}
\hline Topic & Example question \\
\hline Study intervention of child & $\begin{array}{l}\text { How did you experience the physical and/or occupational therapy intervention your child had in the } \\
\text { first six months of the study? }\end{array}$ \\
\hline Therapists' roles during the study & What was the therapists' role during the LEARN 2 MOVE 2-3 study? \\
\hline Intervention goals & How were the goals of the intervention for your child determined? \\
\hline Parents' roles during the study & If it was up to you, how would you as a parent prefer to be involved in your child's intervention? \\
\hline Home visit & Would a home visit have provided added value in your opinion? \\
\hline
\end{tabular}

\section{Table 2}

Key themes resulting from interviews on the experiences and needs of parents of young children (2-4 years of age) with cerebral palsy regarding their child's physical and occupational therapy in a rehabilitation setting.

\begin{tabular}{ll}
\hline Theme & Subtheme \\
\hline Process of parent empowerment & Cerebral Palsy in general \\
& Therapy \\
& Prospects \\
& Attentiveness \\
& Honesty \\
& Partnership \\
& Roles \\
& Involvement \\
\hline
\end{tabular}

